\title{
Piezo-Valve Controller for the gas inlet system of the fusion experiment Wendelstein 7-X
}

\author{
Jörg Schacht ${ }^{\mathrm{a}}$, Jürgen Sachtleben ${ }^{\mathrm{a}}$, Hans Jensen ${ }^{\mathrm{a}}$, Ulli Stutz ${ }^{\mathrm{b}}$, Mathias Wiese ${ }^{\mathrm{b}}$, \\ a Max Planck Institute for Plasma Physics, Wendelsteinstrasse 1, Greifswald, Germany \\ ${ }^{b}$ University of Applied Science Stralsund, Stralsund, Germany,
}

\begin{abstract}
The gas inlet system of the fusion experiment Wendelstein 7-X (W7-X) comprises eleven gas inlets around the torus for controlled provision with working gases in the torus. This fast gas inlet system is designed for different operating modes of W7-X, from short discharges with only a few seconds durations to steady state plasma operation with operation time of 30 minutes. Piezo valves of type FGIS (FGIS: Fast Gas Injection System from General Atomics) are used as actuators for the W7-X gas inlet system.

The design of an intelligent control unit for the FGIS Piezo valves are introduced and discussed. The integration of the valve controller units into the W7-X control component "W7-X gas inlet" and their planned application in an experiment run is described.
\end{abstract}

Keywords: gas inlet system, Piezo electrical valve, valve controller unit,

\section{Introduction}

The fusion experiment Wendelstein 7-X is an advanced stellarator and will be used as a concept test for reactor relevant plasmas. Essential features of W7-X are the fivefold toroidal symmetry and the using of an optimized magnetic field produced by a superconducting magnet system with 50 non-planar and 20 planar coils.

For operation of W7-X and especially for the preparation and execution of plasma experiments many main and auxiliary systems of W7-X have to be supplied with different gas species. The utilized gas species of the gas supply system are separated into two different groups: the gas species for operation (operational gases) and gas species for conditioning purposes (conditioning gases).

Table 1: Classification of gas species of W7-X gas supply system

\begin{tabular}{|c|c|c|c|}
\hline Main group & Sub group & Gas species & Application \\
\hline \multirow[t]{3}{*}{$\begin{array}{l}\text { operational gas } \\
\text { species }\end{array}$} & primary working gases & $\begin{array}{l}\text { Hydrogen, } \\
\text { Deuterium, } \\
\text { Helium, }\end{array}$ & plasma operation \\
\hline & secondary working gases & $\begin{array}{l}\text { Neon, } \\
\text { Argon, } \\
\text { Nitrogen, }\end{array}$ & $\begin{array}{l}\text { For a controlled injection of impurities in the } \\
\text { plasma edge. }\end{array}$ \\
\hline & diagnostic gases & $\begin{array}{l}\text { Hydrogen, } \\
\text { Deuterium, } \\
\text { Inert gases, } \\
\text { Nitrogen }\end{array}$ & $\begin{array}{l}\text { For injection into the plasma for diagnostic } \\
\text { purposes }\end{array}$ \\
\hline \multirow[t]{4}{*}{$\begin{array}{l}\text { Gases for special } \\
\text { purposes }\end{array}$} & conditioning gases & $\begin{array}{l}\text { Hydrogen, } \\
\text { Deuterium, } \\
\text { Helium, }\end{array}$ & $\begin{array}{l}\text { Gases for discharges for a conditioning of the } \\
\text { plasma vessel wall, }\end{array}$ \\
\hline & coating gases & $\begin{array}{l}\text { Diborane, } \\
\text { Silane, } \\
\text { Methane, }\end{array}$ & Gases for a coating of the plasma vessel wall, \\
\hline & gas for cryopumps & Argon & Preparation of cryopumps (Argon frosting) \\
\hline & other applications & Nitrogen & $\begin{array}{l}\text { Gas to wash gas pipes, vacuum pumps, fit- } \\
\text { tings. } \\
\text { Ventilation of plasma vessel and peripheral } \\
\text { vacuum systems }\end{array}$ \\
\hline
\end{tabular}


At W7-X a central gas supply system has been installed which allows a controlled supply of the gases hydrogen, deuterium, helium, nitrogen, methane, rare gases, and mixtures thereof. In addition diborane or silane mixtures can be provided for coating of the inner wall of the plasma vessel. An overview of the necessary gas species for W7-X operation for the different application is summarized in table 1.

The gas inlet system is a main component of the superconducting fusion experiment W7-X. For all W7-X operational phases the gas supply system provides the necessary gas species or gas mixtures for all gas consumers, e.g. for the gas inlet system, diagnostics, and technical components (e.g. water cooling system).

The gas inlet system is used for a controlled gas inlet of different gas species into the plasma vessel during the operational phases of W7-X.

The operational gases contain the working gas species and the gas species for diagnostic purposes during the plasma operation. The requirements for the gas inlet for plasma operation and for conditioning differ. The control rate of the gas flow for plasma operation has to be much faster than the control rate for conditioning. Furthermore, plasma operation requires fast switching between different gas species. The gas inlet system has 11 different positions for a controlled gas inlet into the plasma vessel. Each of the five W7-X modules has its individual location for the gas inlet valves. Due to the various operational modes of W7-X planned [1,2] the gas inlet has to operate both short plasma discharges with a duration up to a few seconds as well as long pulse discharges in the range of 30 minutes.

In this contribution the design for an intelligent control unit for fast gas inlet valves will be shown and discussed. After a brief introduction into the gas supply and distribution system of W7-X the actuator for the fast gas inlet, the piezo-electric valve of type FGIS (Fast Gas Injection System, Fa. General Atomics) as well as the functionality and the construction of the valve controller unit will be explained. The integration of the valve controller units as a part of the component W7-X gas inlet and its application in an experiment run will be described. In the last section the actual status and an outlook of the valve controller unit development project are given.

\section{Outline of the $\mathrm{W} 7-\mathrm{X}$ gas inlet system}

The gas inlet system is designed for a fast switch of the gas sort for every inlet position for operational gases and for a change of the gas sort of the supplying ring lines within an adequate short time period. Fig. 1 shows the structure of the W7-X gas inlet system including the connection to the gas supply system and the exhaust system. Flexible plasma operation demands fast gas inlet controlling. Also a fast switching between the different gas species by switch on or switch of the gas flow of the relevant stubs is an important requirement for flexible plasma operation. The fusion experiment W7-X needs for preparation and processing of plasma experiments different gas species and gas mixtures. The supply of the gases and the mixtures of them for the W7-X experiment and other consumers, e.g. the stellarator experiment "WEGA" or laboratory experiments are realized with a single central gas supply system. Thus the central gas supply system works as an infrastructure component for the W7-X experiment. The control system of the central gas supply is based on a Programmable Logic Controller (PLC) of type Simatic S7-400 (Fa. Siemens). A special safety controller handles all functions in relation of personnel and machine safety. The W7-X gas supply and the W7-X gas inlet system are directly connected via the gas tubes. A system of ring lines will be installed around the W7-X machine in the torus hall and allows an easy connection of different gas inlet positions with the gas tubes of the ring lines. The gas station of the central gas supply system for the gas sort Nitrogen is directly connected with the ring line "RL $\mathrm{N}_{2}$ " and is available for the consumers of Nitrogen in all operational phases of W7-X. A controllable valve matrix with 5 inputs and 4 outputs allows connecting different gas species, which are delivered from the gas stations of the gas supply system, through one of the ring lines 1-4. The ring lines are installed around the W7-X torus. Stubs connect all gas inlet valves with the ring lines. The ring line "coating" is reserved only for an operation with coating gas Diborane and Silane.

The supply of gases into the plasma vessel takes place via dedicated ports. The machine W7-X has altogether 17 ports, dedicated to gas inlet purposes: 3 ports for conditioning, 10 ports for inlet of operational gases, and 5 ports for coating. A mobile gas station can be used for additional gas supply for special gases for diagnostic purposes. A pump station allows an evacuation of all ring lines, which is necessary e.g. for a change of the gas sort in a ring line. Table 2 gives a summary of important requirements for the different gas inlet types. 


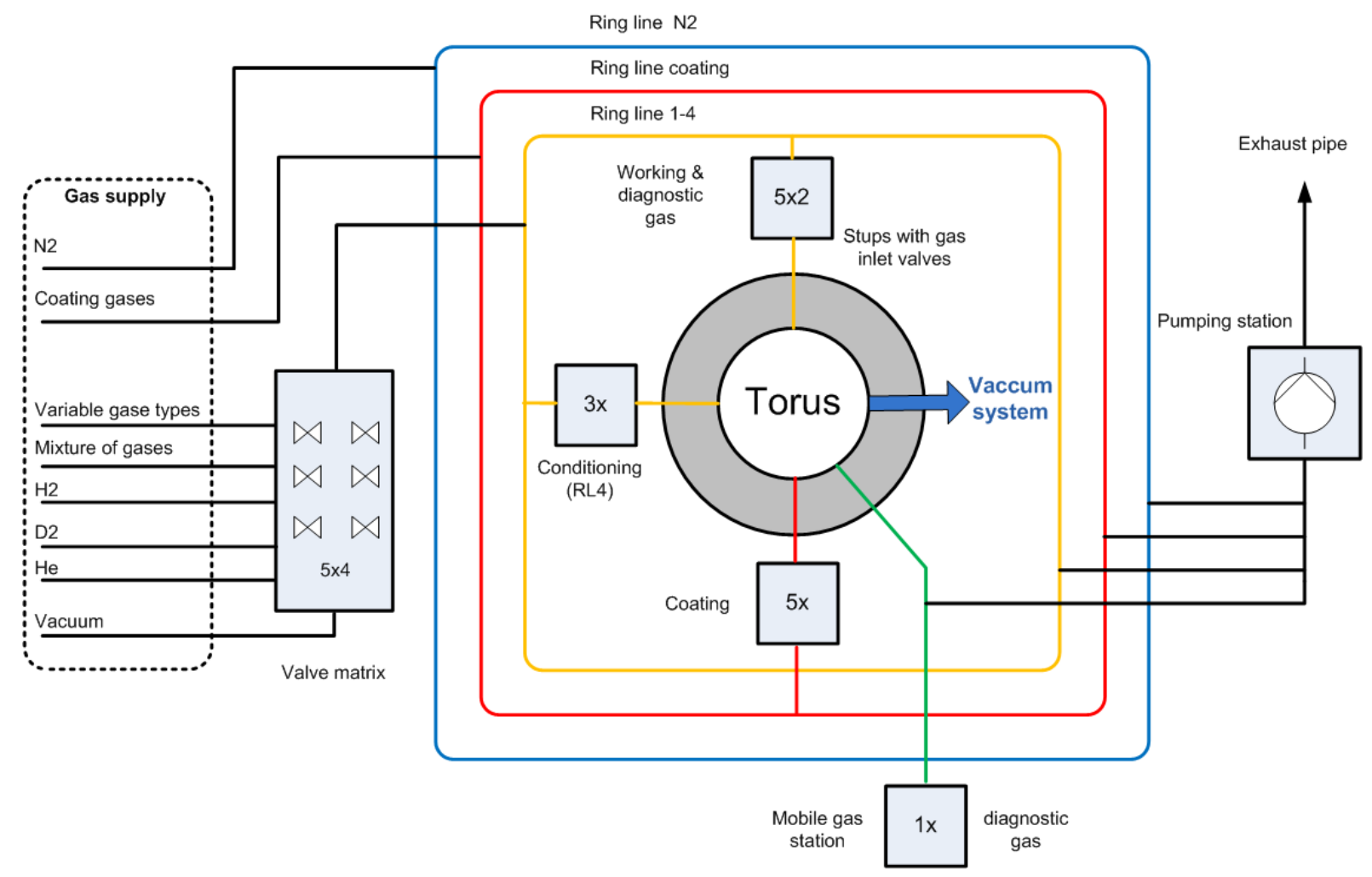

Fig. 1: Schema of the W7-X gas supply system

Table 2: Main requirements for the gas inlet system of W7-X

\begin{tabular}{|c|c|c|}
\hline Gas inlet for: & Requirement & Actuator \\
\hline $\begin{array}{l}\text { Operational } \\
\text { gases }\end{array}$ & $\begin{array}{l}\text { Fast response time for the gas inlet valve in the range of } \mathrm{t}<2 \mathrm{~ms} \text {, } \\
\text { Summarized gas flow } \mathrm{q}_{\mathrm{s}}=500 \mathrm{mbar} 1 \mathrm{~s}^{-1} \text {, } \\
\text { Range of gas flow } \mathrm{q}=1-500 \mathrm{mbar} 1 \mathrm{~s}^{-1} \text {, } \\
\text { Stable and a calibrated measurement of gas flow independent of } \\
\text { system pressure, } \\
\text { System pressure } \mathrm{p}=2 \mathrm{bar} \text {, } \\
\text { Applicability for all operational gas species, } \\
\text { Valves must be operable for continuous operation in a magnet field. } \\
\text { Change of the gas sort during experiment operation. }\end{array}$ & Piezo valves FGIS \\
\hline Conditioning & $\begin{array}{l}\text { Response time for the gas inlet valve in the range of } \mathrm{t}<200 \mathrm{~ms} \text {, } \\
\text { Measurement of gas flow using mass flow controllers. } \\
\text { System pressure } \mathrm{p}=2 \mathrm{bar} \text {, } \\
\text { Applicability for all conditioning gas species, } \\
\text { Valves must be operable for continuous operation in a magnet field. } \\
\text { Feedback controlled gas inlet into the plasma vessel for a pressure } \\
\text { range of } 10^{-5}-10^{-2} \text { mbar, }\end{array}$ & Proportional valves \\
\hline Coating & $\begin{array}{l}\text { Response time for the gas inlet valve in the range of } \mathrm{t}<200 \mathrm{~ms} \text {, } \\
\text { System pressure } \mathrm{p}=2 \mathrm{bar} \text {, } \\
\text { Applicability for all aggressive and corrosive coating gas species, } \\
\text { Feedback controlled gas inlet into the plasma vessel for a pressure } \\
\text { range of } 10^{-5}-10^{-2} \text { mbar, }\end{array}$ & Proportional valves \\
\hline $\begin{array}{l}\mathrm{N}_{2} \text { venting of } \\
\text { plasma vessel }\end{array}$ & $\begin{array}{l}\text { The venting shall be done in a period of max. } 3 \mathrm{~h}\left(\mathrm{~V}_{\text {Vessel }}=100 \mathrm{~m}^{3}\right) \text {; } \\
\text { The necessary mass flow of } \mathrm{N}_{2} \text { has to be } \mathrm{q}=10.000 \mathrm{mbar} 1 \mathrm{~s}^{-1} \text {, }\end{array}$ & Proportional valves \\
\hline
\end{tabular}




\section{Description of W7-X component gas inlet}

The planned structure of the component gas inlet is done in compliance with the generic W7-X control component. Fig. 2 gives an overview about the internal architecture of this component and its interfaces to the central control system of W7-X.

For a fast gas inlet into the plasma vessel 11 FGIS valves are used. Every piezo-electric valve is directly connected to valve controller unit. The fast control station (FCS), an industrial computer, running with a real time operating system (VxWorks, Fa. Wind River) controls all connected 11 valve units via a field bus connection. The type of the field bus is EtherCat. Due to the coupling of the FCS with valve units via EtherCat field bus it is possible to fulfill easily the hard real time requirements. The cycle time for output of gas flow set values is required in a range of $1 \mathrm{~ms}$.

The FCS is equipped with controllable modules for different purposes, e.g. modules for processing the experiment program definitions, modules for the communication with internal and external control components, and also with modules for signal processing and controlling. If necessary, a controller can feed back control the gas flow of the 11 piezo-electric valves in dependence of the actual plasma density value.

A PLC is responsible for all tasks of the operational management and for all slow real time measurement and control tasks of the component gas inlet. Furthermore, the PLC provides human machine interface (HMI) for supervision and visualization, realized with the application program WinCC, Fa. Siemens.

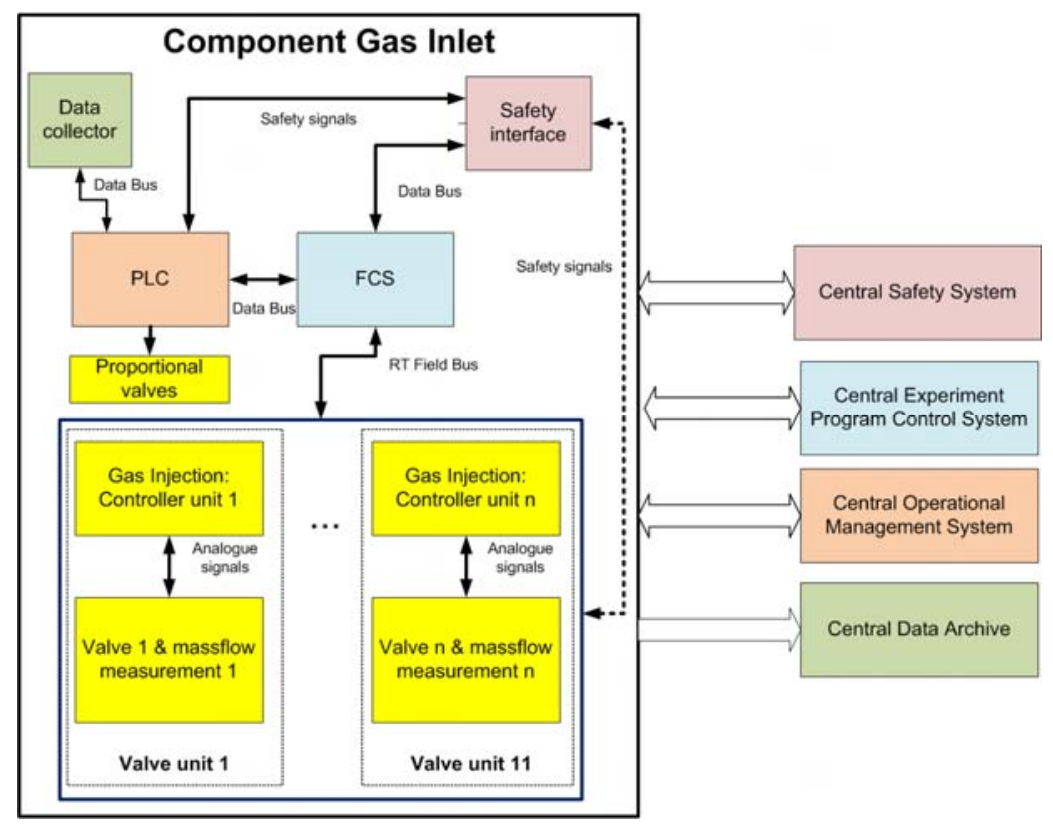

Fig. 2: Integration of the valve unit within gas inlet system

The component gas inlet is connected via multiple interfaces to the sub systems of central control system and the data bases for the configuration, experiment programs and data archives [Referenz].

\section{Piezo-electric valve FGIS}

The gas valve FGIS for gas inlet of the operational gases is a piezo-electrical inlet valve which can achieve a maximum gas flow rate of $666 \mathrm{mbar}$ 1/s (gas sort $\mathrm{H} 2$ at 6.5 barA operating pressure). The opening time of the valve is $\leq 2 \mathrm{~ms}$ after applying a voltage on the piezo stack. The rising time is specified by the manufacture general Atomics in a range $\leq 0.5 \mathrm{~ms}$ with a following transient effect of $<2 \mathrm{~ms}$. The decay time is $\leq 0.3 \mathrm{~ms}$. The FGIS valve can work in a magnet field up to $2.4 \mathrm{~T}$ and can be fitted without any restriction on a flange at the W7-X cryostat. Fig. 3 shows the mechanical assembly of a FGIS valve. The length of this valve is about $180 \mathrm{~mm}$. Each valve of a valve unit must be calibrated. Two types of calibration exits: the factory calibration, and calibration during the operation (in situ calibration).

\section{Control unit for the FGIS valves}


For reasons of a flexible usage of valve controller units at W7-X or other range of applications every piezoelectric valve FGIS is connected with a separate controller and electronics. It gives the opportunity for placing the valve controller units locally separated at an optimized mounting position close to the valve units. A valve unit is a combination of a piezo-electric valve and control valves as shown as in Fig. 4. The valve controller unit consists of the sub units power supply, a controller with interface modules, high voltage amplifier and visualization and control. The power supply generates all required supply voltages with necessary power for the consumers of the valve controller unit. The power supply for the high voltage amplifier with a voltage level of $300 \mathrm{~V}$ needs a special effort. The processing unit of the valve controller is an embedded controller IPC@Chip ${ }^{\circledR}$ SC143, Fa. Beck IPC GmbH / Germany. The SC143 chip is a combination of hardware (16 bit 186 processor, 8 MByte RAM, 8 MByte Flash) and software including the preinstalled real time operating system, TCP/IP stack, and FTP server.

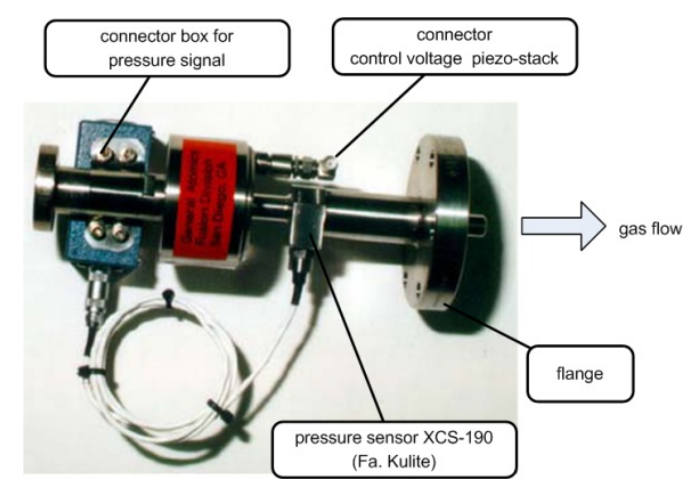

Fig. 3: Fast Gas Injection System of Fa. General Atomics

The processing unit is equipped with an EtherCat network interface for communication with the FCS of the gas inlet component. EtherCAT is the open real-time Ethernet network originally developed by Beckhoff. The functionality of the EtherCat interface is encapsulated in an ASIC as a part of an EtherCAT Slave Controller (ESC). The ESC FB 1130 Piggyback controller board, Fa. Beckhoff, handles all time-critical tasks in the slave, so that there are no demands for processor power from the communication side [Referenz Beckhoff]. An internal PID controller for the gas flow through the FGIS valve guarantees a minimal cycle time of $t_{\text {cycle }}=0.1 \mathrm{~ms}$. All measurement values, messages and status information must be combined with a time stamp [3,4]. The time counter of the processing unit should be synchronized with the W7-X system time with an accuracy of $\leq 100 \mu$ s. Several I/O ports of the controller connect the elements for signaling, operation and the LCD display. Fig. 4 depicts the architecture of the valve controller unit. For an operation of the valve controller unit a set of 4 different operational modes can be used. A short description of these operational modes is given in Table 3 .

Table 3: Description of the operational modes of the valve controller unit

\begin{tabular}{|c|c|c|c|}
\hline No. & Operational mode & Access mode & Description \\
\hline 1 & Valve control & autonomous & $\begin{array}{l}\text { The valve controller unit works independent from the FCS. } \\
\text { The valve can be controlled by input of set points or by } \\
\text { choosing a predefined program containing a chain of set } \\
\text { points. } \\
\text { Alternatively it is possible to controls the valve by analogue } \\
\text { input signal in a range of } 0-10 \mathrm{~V} \text {. }\end{array}$ \\
\hline & & subordinated & $\begin{array}{l}\text { The valve controller unit works as a slave of the FCS. } \\
\text { The FSC controls the valve by sending the set point cyclical- } \\
\text { ly to the valve control unit via the field bus. } \\
\text { This mode is used for W7-X experiment operation. }\end{array}$ \\
\hline 2 & Test & autonomous & $\begin{array}{l}\text { In this mode a self test of the control unit hardware and user } \\
\text { specified tests can be realized. }\end{array}$ \\
\hline 3 & Configuration & autonomous & $\begin{array}{l}\text { All possible set ups for a configuration of the valve control } \\
\text { unit is possible in the configuration mode. }\end{array}$ \\
\hline 4 & Calibration & autonomous & Processing of the in-situ calibration of the valve. \\
\hline
\end{tabular}

\section{Design of the analogue part for valve control}


The analogue parts for control and monitor the FGIS valve includes generation of the control voltage $\mathrm{U}_{\mathrm{PV}}(0-300$ $\mathrm{V}$ ), the generation of a monitor signal for $\mathrm{U}_{\mathrm{PV}}$, and the measurement of the pressure signal, coming from the pressure sensor XCS-190, Fa. Kulite. An overview of the analogue part is shown in Fig.5. If the appropriate operational mode is active, the set point for the valve opening is set by the controller unit via a 12 bit Digital to Analogue Converter (DAC). A following pre-amplifier transforms the output voltage of the DAC into the input range of the following high voltage amplifier (PA 95 / Cirrus Logic). The PA 95 then generates the necessary high voltage in a range of $0-300 \mathrm{~V}$ for the control of the FGIS valve. The gain factors for these amplifier stages are set to $\mathrm{V}_{\mathrm{PA}}=2$ und $\mathrm{V}_{\mathrm{A}}=30$. For monitor purposes the valve control voltage is monitored. For monitoring purposes the valve control voltage is divided in a ratio of 1:30. A 12 bit Analogue to Digital Converter (ADC) digitizes this monitor voltage. The analogue measurement signal of the pressure sensor XC-190 has a full range value of $U_{p}=200 \mathrm{mV}$. The following pre-amplifier transforms the sensor output voltage in a range, optimized for the given input range of the connected ADC channel. The selected 12 bit ADC device has an input signal range of $\mathrm{U}_{\mathrm{ADC}}=0-5 \mathrm{~V}$, and therefore the gain factor of the pre-amplifier is set to 25 . The measurement chain for gas pressure acquisition with the XC-190 sensor enables a resolution of 0.244 mbar. In principle all of the controller's analogue input and output channels have a galvanic decoupling to the sensor and actuator for electromagnetic compatibility (EMC) reasons.

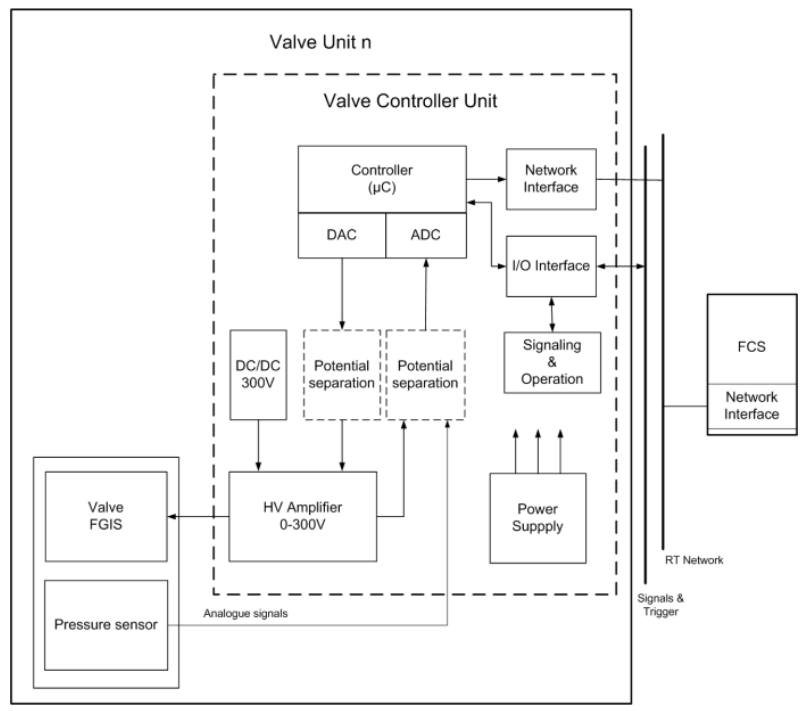

Fig. 4: Design of a valve controller unit

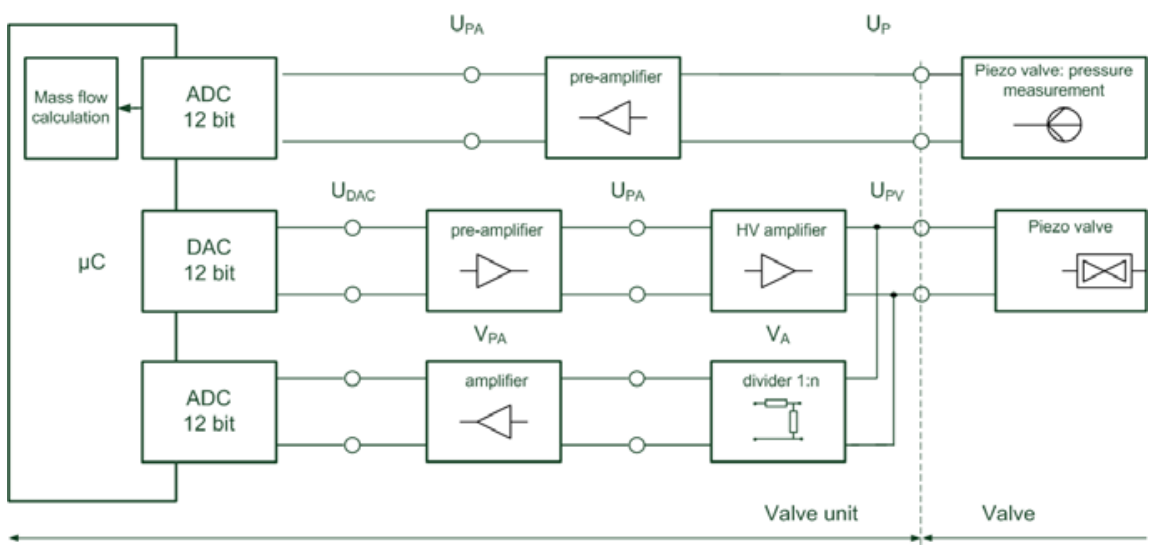

Fig.5: Analogue part of valve control and acquisition of the pressure signal

\section{Technical realization of the valve control unit}

The valve control unit is designed as a stand-alone device. A 19" module rack (Fa. Schroff GmbH) is equipped with modules for the power supply, a module for the embedded controller, a module for the analogue electronics, and a module for the LCD display and input keys. Via a back plane all modules are supplies with power from the power module. Also the signal transfer between the modules is realized by bus signal lines of the back plane. The assembly locations of different sub-systems of the gas inlet system are shown in Fig. 6. The length of the 
gas flow path from FGIs valve into the plasma vessel is less than $2 \mathrm{~m}$. The valve FGIS, equipped with the pressure sensor XC-190, and additional proportional valves are designed as a constructional unit (valve box unit: VBU). The mounting locations of these VBUs are outside of the W7-X cryostat close to the gas inlet ports. The valves and the sensors of the VBUs are connected to the valve controller and the component PLC via control and signal cables. The lengths of the control cable for the FGS valves should be no longer than $30 \mathrm{~m}$, because the cable length has a direct impact on characteristic parameters for the valve control signal. Therefore the 11 valve control units are distributed around the W7-X machine in the torus hall.

Every valve control unit is connected to the control system of the component gas inlet via networks. The location of the cubicle for the main control systems of the gas inlet, e.g. for the PLC and the FCS, is the rack shelf into the torus hall.

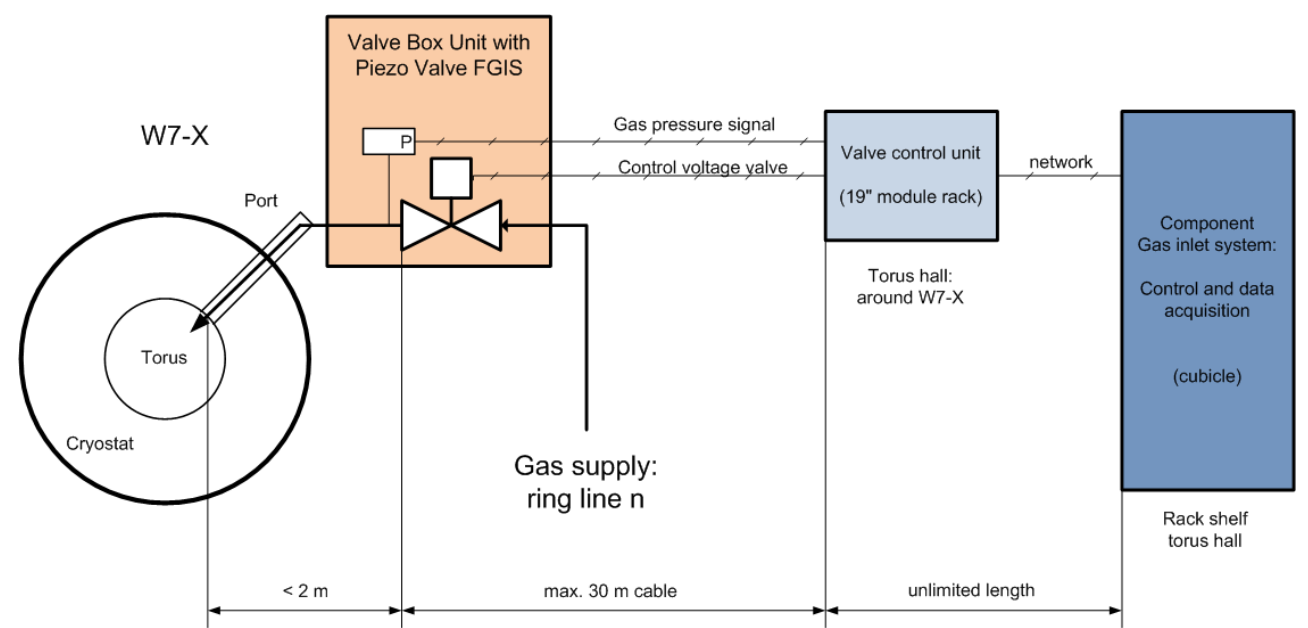

Fig. 6: Distribution of main parts of the gas inlet system at W7-X

\section{Status and outlook}

The specification for the valve control unit is finished. Currently the electronic modules for the FGIs valve control and data acquisition will be developed and tested.

A DK-61 development board (Fa. Beck) and an EtherCat bus module FB1120 from Beckhoff are used as test equipment for the controller module. After a successful software development and test of all I/O and network interfaces the printed circuit for the controller module will be designed.

The next step after the development of the valve control unit will be then setup of the whole W7-X control component gas inlet.

Finally, the W7-X testbed WEGA (a stellarator experiment at IPP Greifswald) [5,6] will be used for a test of the fast gas inlet with real experimental conditions.

\section{References}

[1] J. Schacht, H. Niedermeyer, H. Laqua, Task and structure of the WENDELSTEIN 7-X control system, Fusion engineering and Design 81(2006) 1799-1806.

[2] H. Laqua, H. Niedermeyer, J. Schacht. Control System of Wendelstein 7-X Experiment, Fusion Engineering and Design 66-68, 669-673, 2003.

[3] J. Schacht, H. Niedermeyer, J. Hildebrandt, Chr. Wiencke, The Trigger-Time-Event System for the W7-X Experiment, 3 rd. IAEA Technical Committee Meeting on Control, Data Acquisition and Remote Participation for Fusion Research, Padova 2001.

[4] J. Schacht, H. Laqua, H. Niedermeyer: Synchronization of processes in a distributed real time system exemplified by the control system of the fusion experiment WENDELSTEIN 7-X, Proceedings of the 14th IEEE Real Time Conference on nuclear and plasma science, Stockholm, May 2005.

[5] J. Schacht, et al., Stellarator WEGA as a test-bed for the WENDELSTEIN 7-X control system concepts, Fusion Eng Des (2008), Volume 83, issues2-3, April 2008.

[6] J. Schacht, et al., Overview and status of the prototype project for Wendelstein 7-X control system, SOFT conference, Rostock, Sept. 2008, will be published in Fusion engineering and design. 